\title{
PENGARUH PEMBERIAN EKSTRAK TAUGE DAN BAWANG MERAH PADA PERTUMBUHAN BIBIT GAHARU (Aquilaria malaccensis)
}

\author{
The Influence of Giving Bean Sprout and Red Onion Extract to The Growth of Agarwood \\ Seedlin
}

\author{
Fenty Dwi Jayanti, Duryat dan Afif Bintoro
}

Jurusan Kehutanan Fakultas Pertanian Universitas Lampung

Jl. Prof. Dr. Soemantri Brojonegoro No. 1, Bandar Lampung.

Email : fentydwijayanti7@gmail.com

\begin{abstract}
Agarwood is a plant that has high economic value and its demand continues to increase from time to time, therefore it is necessary to provide a natural hormones to help the growth of agarwood seedlings to have good quality and quantity. The purpose of study ware to determine the effect of extract bean sprouts application and onion extract application to increase the growth of A.malaccensis seedlings and to find out the best dosage of bean sprout extract and onion extract to increase the seedling growth. The study was designed in a complete randomized design (CRD) in 9 treatments namely control, bean sprout extract at the dose of $100 \mathrm{~g} / \mathrm{l}, 200 \mathrm{~g} / \mathrm{l}, 300 \mathrm{~g} / \mathrm{l}, 400 \mathrm{~g} / \mathrm{l}$ and onion extract at the dose of $100 \mathrm{~g} / \mathrm{l}, 200 \mathrm{~g} / \mathrm{l}, 300 \mathrm{~g} / \mathrm{l}$, and $400 \mathrm{~g} / \mathrm{l}$. The homogeneity test, analysis of variance and LSD test were employed as the data analysis. The results of study showed that bean sprouts and onion extract application, have a significant effect to the increasing of height (up to $11,47 \mathrm{~cm}$ on the treatment onion extract at a dose of $200 \mathrm{~g} / \mathrm{l}$ ), number of leaves (up to 9,67 leaves on the treatment onion extract at a dose of $200 \mathrm{~g} / \mathrm{l}$ ), and seedling quality index (up to $0,18$ on the treatment onion extract at a dose of $200 \mathrm{~g} / \mathrm{l})$. The best treatment to the increase of A.malaccensis seedlings was the onion extract application at a dose of $200 \mathrm{~g} / \mathrm{l}$. The treatment can be applied in agarwood seeds to get maximum results.
\end{abstract}

Keyword : A.malaccensis; plant growth regulator; onion; bean sprout.

\section{ABSTRAK}

Gaharu merupakan tanaman yang memiliki nilai ekonomi tinggi dan permintaannya terus meningkat dari waktu ke waktu, oleh karena itu diperlukan pemberian hormon alami untuk membantu pertumbuhan bibit gaharu agar memiliki kualitas dan kuantitas yang baik. Tujuan dari penelitian ini yaitu untuk mengetahui pengaruh pemberian ekstrak kecambah kacang hijau (tauge) dan bawang merah terhadap pertumbuhan bibit A.malaccensis serta mengetahui dosis yang paling baik untuk meningkatkan pertumbuhan bibit. Penelitian ini dirancang menggunakan rancangan acak lengkap (RAL) dengan 9 perlakuan yaitu kontrol, pemberian ekstrak tauge dengan dosis $100 \mathrm{~g} / \mathrm{l}, 200 \mathrm{~g} / \mathrm{l}, 300 \mathrm{~g} / \mathrm{l}, 400 \mathrm{~g} / \mathrm{l}$ serta pemberian ekstrak bawang merah dengan dosis $100 \mathrm{~g} / \mathrm{l}, 200 \mathrm{~g} / \mathrm{l}, 300 \mathrm{~g} / \mathrm{l}$, dan $400 \mathrm{~g} / \mathrm{l}$. Analisis data yang digunakan yaitu uji homogenitas ragam, analisis ragam dan uji BNT. Hasil dari penelitian menunjukkan bahwa pemberian ekstrak tauge dan bawang merah memiliki pengaruh yang nyata terhadap pertumbuhan tinggi (sampai dengan 11,47 pada perlakuan pemberian ekstrak bawang merah $200 \mathrm{~g} / \mathrm{l}$ ), jumlah daun (sampai dengan 9,67 helai pada perlakuan pemberian ekstrak bawang $200 \mathrm{~g} / \mathrm{l}$ ), dan indeks mutu bibit (sampai dengan 0,18 pada perlakuan pemberian ekstrak bawang merah $200 \mathrm{~g} / \mathrm{l})$. Pelakuan terbaik untuk 
pertumbuhan bibit A.malaccensis yaitu pemberian ekstrak bawang merah dengan dosis 200 g/l. perlakuan tersebut dapat diaplikasikan pada bibit gaharu untuk mendapatkan hasil yang maksimal.

Kata kunci : A.malaccensis, ZPT, tauge, bawang merah.

\section{PENDAHULUAN}

Gaharu (Aquilaria malaccensis) merupakan salah satu tanaman nonkayu yang memiliki nilai ekonomi yang tinggi (Whaitmore, 1980) karena resin pada pohon ini dapat digunakan sebagai bahan baku membuat parfum, sabun, pengobatan dan lain sebagainya. Banyaknya kegunaan pohon tersebut menyebabkan permintaan pasar nasional maupun internasional terus meningkat. Peningkatan permintaan tersebut menyebabkan pohon jenis ini banyak ditebang di hutan secara berlebihan, sehingga sulit menemukan jenis pohon tersebut di alam. Selain itu, kelemahan pada pohon ini tidak berbuah sepanjang tahun dan biji yang tidak dapat disimpan dalam jangka waktu yang lama, sehingga anakan yang sulit ditemukan di hutan (Situmorang, 2000).

Tahun 1995 pohon gaharu telah masuk dalam IUCN (International Union for the Conservation of Nature and Natural Resources) red list, IUCN melalui pemerintah memberikan arahan kepada negara pengekspor gubal gaharu untuk lebih memproduksi gaharunya saja (Rahayu dan Situmorang, 2004). Memiliki sumber benih yang baik secara kualitas maupun kuantitas yang berasal dari hasil budidaya maupun yang berasal dari alam merupakan salah satu upaya untuk pelestarian jenis ini. Salah satu menghasilkan bibit yang berkualitas serta dengan jangka waktu yang singkat maka diperlukannya perlakuan khusus pada bibit salah satunya pemberian zat pengatur tumbuh (ZPT).

ZPT merupakan senyawa organik bukan hara yang mendukung proses fisiologis tumbuhan. ZPT dapat dibagi menjadi 2 jenis yaitu ZPT kimia dan ZPT alami, contoh ZPT alami yaitu kecambah kacang hijau (tauge), serta bawang merah. Hal ini dikarenakan bawang merah dan kecambah kacang hijau (tauge) memiliki kandungan auksin dan giberelin yang berfungsi memacu pertumbuhan akar. Menurut Wardoyo (1996) pemberian ekstrak bawang merah dengan dosis $150 \mathrm{~g} / \mathrm{l}$ merupakan dosis yang efektif untuk pertumbuhan cabang Pterocarpus indicus. Sedangkan menurut Rauzana dkk., (2017) pemberian ekstrak tauge berpengaruh nyata terhadap panjang tunas, panjang akar, dan jumlah daun pada pertumbuhan bibit lada dengan konsentrasi $300 \mathrm{ml} /$ liter. Tujuan penelitian ini yaitu untuk mengetahui pengaruh pemberian ekstrak tauge dan bawang merah terhadap pertumbuhan bibit gaharu.

\section{METODE}

Penelitian ini dilaksanakan pada bulan Maret - Juni 2018 di rumah kaca Fakultas Pertanian dan Laboratorium Jurusan Kehutanan Universitas Lampung. Bahan yang digunakan meliputi bibit gaharu (A.malaccensis) sebagai tumbuhan yang akan diuji, bawang merah dan kecambah kacang hijau yang digunakan sebagai ekstrak untuk ZPT. Alat yang digunakan meliputi timbangan digital, blender, gelas ukur, pisau, penggaris, handspray, caliper, benang, dan pita meter.

Penelitian ini dirancang dalam Rancangan Acak Lengkap (RAL) yang terdiri dari 9 perlakuan yaitu control (CO), $100 \mathrm{~g}$ bawang merah/liter air $\left(\mathrm{B}_{1}\right), 200 \mathrm{~g}$ bawang merah/liter air $\left(\mathrm{B}_{2}\right), 300 \mathrm{~g}$ bawang merah/liter air $\left(\mathrm{B}_{3}\right), 400 \mathrm{~g}$ bawang merah/liter air $\left(\mathrm{B}_{4}\right), 100 \mathrm{~g}$ kecambah kacang hijau/liter air $\left(\mathrm{K}_{1}\right), 200 \mathrm{~g}$ kecambah kacang hijau/liter air $\left(\mathrm{K}_{2}\right), 300 \mathrm{~g}$ kecambah kacang hijau/liter air $\left(\mathrm{K}_{3}\right)$, dan $400 \mathrm{~g}$ kecambah kacang hijau/liter air $\left(\mathrm{K}_{4}\right)$. Masing-masing 
perlakuan diulang sebanyak 3 kali, setiap satuan percobaan terdiri dari 5 bibit A.malaccensis sehingga total keseluruhan berjumlah 135 bibit.

Aplikasi ekstrak bawang merah dan kecambah kacang hijau dengan cara disemprotkan secara merata, pengaplikasian dengan cara diseprot dirasa cukup efektif untuk membantu dalam pertumbuhan bibit A.malaccensis dikarenakan hormon dan unsur hara dapat diserap melalui stomata dibagian bawah daun atau melalui celah epidermis dipermukaan daun bagian atas (Trubus, 2010). Pengaplikasian ekstrak dilakukan pada hari ketujuh setelah pemindahan A.malaccensis ke polybag. Penyemprotan dilakukan setiap 1 minggu sekali selama 3 bulan penelitian.

Parameter pengamatan meliputi tinggi tanaman, jumlah daun, panjang akar, penambahan diameter, dan indeks mutu bibit (IMB). Hasil data dianalisis dengan uji homogenitas ragam, setelah data homogen dilakukan uji ragam (ANOVA). Apabila $F_{\text {hitung }}>$ $F_{\text {tabel, }}$ maka dapat dilakukan uji lanjut menggunakan uji beda nyata terkecil (BNT).

\section{HASIL dan PEMBAHASAN}

Pemberian ekstrak tauge dan bawang merah dengan dosis berapapun mampu meningkatkan pertumbuhan bibit A.malaccensis (Tabel 1), dengan dosis terbaiknya yaitu pemberian ekstrak bawang merah $200 \mathrm{~g} / \mathrm{l}$ dengan rata-rata pertumbuhannya yaitu $11,47 \mathrm{~cm}$, hal tersebut menunjukkan bahwa dosis yang diterima oleh tanaman sudah efektif dengan pemberian dosis tersebut.

Tabel 1. Hasil uji beda nyata terkecil (BNT) pada parameter tinggi bibit Table 1. LSD test results on seedling height parameters

\begin{tabular}{ccc}
\hline \multirow{2}{*}{ Perlakuan $(\mathrm{g} / \mathrm{l})$} & \multicolumn{2}{c}{ Parameter Penambahan Tinggi } \\
\cline { 2 - 3 } & Rata-rata $(\mathrm{cm})$ & Notasi \\
\hline Kontrol & 6,60 & $\mathrm{~b}$ \\
Tauge 100 & 9,73 & $\mathrm{a}$ \\
Tauge 200 & 9,37 & $\mathrm{a}$ \\
Tauge 300 & 10,57 & $\mathrm{a}$ \\
Tauge 400 & 9,47 & $\mathrm{a}$ \\
Bawang merah 100 & 10,80 & $\mathrm{a}$ \\
Bawang merah 200 & 11,47 & $\mathrm{a}$ \\
Bawang merah 300 & 10,53 & $\mathrm{a}$ \\
Bawang merah 400 & 10,13 & $\mathrm{a}$ \\
\hline \multicolumn{2}{c}{ BNT 2,57 }
\end{tabular}

Ekstrak tauge dan bawang merah memiliki fitohormon yaitu auksin. Menurut Ulfa (2014) dan Khair dkk. (2013) bahwa kecambah kacang hijau (tauge) dan bawang merah mengandung hormon alami yaitu hormon auksin. Dimana hormon auksin memiliki fungsi dalam pengembangan sel, pertumbuhan akar, fototropisme, geotropism, partenokarpi, apikal dominan, pembentukan kalus dan repirasi (Abidin, 1993). 
Tabel 2. Hasil uji beda nyata terkecil (BNT) parameter jumlah daun

Table 2. LSD test results on seedling number of leaves parameters

\begin{tabular}{lcc}
\hline \multirow{2}{*}{ Perlakuan $(\mathrm{g} / \mathrm{l})$} & \multicolumn{2}{c}{ Parameter Jumlah Daun } \\
\cline { 2 - 3 } & Rata-rata (helai) & Notasi \\
\hline Kontrol & 3,33 & $\mathrm{~d}$ \\
Tauge 100 & 7,00 & $\mathrm{c}$ \\
Tauge 200 & 9,33 & $\mathrm{ab}$ \\
Tauge 300 & 8,00 & $\mathrm{abc}$ \\
Tauge 400 & 7,00 & $\mathrm{c}$ \\
Bawang merah 100 & 9,33 & $\mathrm{ab}$ \\
Bawang merah 200 & 9,67 & $\mathrm{a}$ \\
Bawang merah 300 & 7,67 & $\mathrm{bc}$ \\
Bawang merah 400 & 8,00 & $\mathrm{abc}$ \\
\hline \multicolumn{2}{c}{ BNT } & \multicolumn{2}{c}{ 1,95 }
\end{tabular}

Sumber (source) : Data primer (2018).

Pemberian ekstrak bawang merah dapat mengikatkan jumlah daun bibit A.malaccensis, dapat dilihat bahwa perlakuan terbaik terdapat pada pemberian ekstrak bawang merah dengan dosis $200 \mathrm{~g} / \mathrm{l}$ (Tabel 2) dengan rata-rata pertumbuhan jumlah daun yaitu 9,67. Hal tersebut diduga karena kandungan hormon auksin yang ada pada kandungan bawang merah dan tauge berperan membantu proses pemanjangan sel secara vertikal dan membantu dalam perbanyakan jumlah daun.

Menurut Artanti (2007) salah satu fungsi auksin yaitu membantu proses pemanjangan sel pada pucuk tanaman, sehingga secara tidak langsung membantu dalam perbanyakan jumlah daun. Semakin tinggi batang maka akan semakin banyak pula daun yang ada pada batang (Siregar dkk., 2015). Sebagaimana penelitian yang dilakukan oleh Taringan dkk. (2017) pemberian ekstrak bawang merah memberikan hasil yang lebih baik terhadap persentase stek lada ketika munculnya tunas, panjang tunas, jumlah daun, dll. Menurut Susanti (2011) pemberian fitrat bawang merah yang diberikan pada stek jambu air lebih optimal dibandingkan dengan pemberian Rootone- $F$.

Tabel 3. Hasil uji beda nyata terkecil (BNT) parameter indeks mutu bibit (IMB) Table 3. LSD test results on seedling quality index parameters

\begin{tabular}{lcc}
\hline \multirow{2}{*}{ Perlakuan $(\mathrm{g} / \mathrm{l})$} & \multicolumn{2}{c}{ Parameter } \\
\cline { 2 - 3 } & \multicolumn{2}{c}{ Indeks Mutu Bibit (IMB) } \\
\cline { 2 - 3 } Kontrol & 0,07 & notasi \\
Tauge 100 & 0,08 & $\mathrm{~d}$ \\
Tauge 200 & 0,13 & $\mathrm{~cd}$ \\
Tauge 300 & 0,11 & $\mathrm{~b}$ \\
Tauge 400 & 0,09 & bcd \\
Bawang merah 100 & 0,12 & bc \\
Bawang merah 200 & 0,18 & $\mathrm{a}$ \\
Bawang merah 300 & 0,10 & bcd \\
Bawang merah 400 & 0,10 & bcd \\
\hline \multicolumn{2}{c}{ BNT } & \multicolumn{2}{c}{0,05} \\
\hline
\end{tabular}

Sumber (source) : Data primer (2018). 
Pemberian ekstrak bawang merah dengan dosis $200 \mathrm{~g} / \mathrm{l}$ merupakan perlakuan terbaik dengan nilai rata-rata 0,18 (Tabel 3). Hal tersebut diduga bahwa ekstrak bawang merah dan tauge merupakan bahan organik yang dapat diurai oleh mikroorganisme yang ada didalam tanah, sehingga dapat dimafaatkan oleh tanaman sebagai nutrisi berupa unsur hara. Namun, unsur hara yang berlebih tidak dapat dimanfaatkan oleh tanaman, sebagaimana menurut Hairiah ddk. (2002) pelepasan unsur hara dalam jumlah yang banyak tidak akan termanfaatkan oleh tanaman, sehingga dapat hilang melalui pencucian maupun penguapan.

Menurut Pidjath (2006) IMB berkaitan dengan unsur hara, seperti unsur hara makro dan mikro yang dapat membantu dalam peningkatan IMB. Hendromono (2003) menyatakan semakin besar IMB maka semakin baik pula tanaman tersebut untuk ditanam di lapangan, apabila IMB lebih dari 0,09 maka bibit tersebut siap untuk ditanam di lapang (Sudomo dan Santoso, 2011).

\section{KESIMPULAN dan SARAN}

Pemberian ekstrak tauge dan bawang merah memiliki pengaruh yang nyata terhadap pertumbuhan tinggi, jumlah daun, dan indeks mutu bibit (IMB) A.malaccensis. Namun, untuk perlakuan terbaik antara pemberian ekstrak bawang merah dan tauge, yaitu terdapat pada pemberian ekstrak bawang merah. Sehingga apabila penelitian ini ingin diaplikasikan pada tanaman, disarankan untuk menggunkan ekstrak bawang merah dengan dosis $200 \mathrm{~g} / \mathrm{l}$ hal tersebut dikarenakan dari penelitian ini perlakuan tersebut merupakan perlakuan terbaik untuk pertumbuhan bibit $A$.malaccensis.

\section{DAFTAR PUSTAKA}

Abidin, Z. (1993). Dasar-Dasar Pengetahuan Tentang Zat Pengatur Tumbuh. Bandung: Angkasa.

Artanti, F. Y. (2007). Pengaruh Macam Pupuk Organik Cair dan Konsentrasi IAA Terhadap Pertumbuhan Setek Tanaman Stevia (Stevia rebaudiana Bertoni M.). [Skripsi]. Surakarta: Universitas Sebelas Maret.

Hairiah, K., Widianto dan Sunaryo. (2004). Ketebalan Seresa Sebagai Indikator Daerah Aliran Sungai (DAS) Sehat. Malang: World Agroforestry Centre, Universitas Brawijaya.

Hendromono. (2003). Kriteria Penilaian Mutu Bibit dalam Wadah yang Siap Tanam untuk Rehabilitasi Hutan dan Lahan. Bogor: Buletin Litbang Kehutanan.Vol. 4(3) Puslitbang Hutan dan Konversi Alam.

Khair, H., Meizal dan Hamdani, Z.R. (2013). Pengaruh konsentrasi ekstrak bawang merah dan air kelapa terhadap pertumbuhan stek tanaman melati putih (Jasminum sambac L.). Jurnal Agrium,18(2), 130-138.

Pidjath, C. 2006. Kualitas Bibit Acacia Crassicarpa A. Cun. Ex Benth. Hasil Sinergi Bioorganic dengan Cendawan Mikoriza Arbuskular Di Ultisol. [Tesis]. Bogor: Institut Pertanian Bogor.

Rahayu ,G dan Situmorang, J. (2006). Menuju Produksi Senyawa Gaharu secara Lestari. Bogor: Laporan Penelitian Hibah Bersaing XI, Lembaga Penelitian dan Pemberdayaan Masyarat IPB.

Rauzana, A, Marlina dan Mariana. 2017. Pengaruh pemberian ekstrak tauge terhadap pertumbuhan bibit lada (Piper nigrum Linn). Jurnal Agrotropika Hayati, 4(3), 178-186. 
Siregar, A.P., Zuhry, E dan Sampoerno. 2015. Pertumbuhan bibit gaharu (Aquilaria malaccensis) dengan pemberian zat pengatur tumbuh asal bawang merah. Jurnal Jom Faperta, 2(1), 1-10.

Situmorang, J. (20000. Mikropropagasi Kayu Gaharu (Aquilaria spp.) Asal Riau Serta Identifikasi Sifat Genetiknya Berdasarkan Analisa Isoenzim. [Tesis]. Bogor: Institut Pertanian Bogor.

Susanti, E. (2011). Pengaruh Pemberian Berbagai Konsentrasi Filtrat Umbi Bawang Merah (allium ascolanicum L.) dan Rootone-f Terhadap Pertumbuhan Vegetatif Tanaman Jambu Air (Syzygium aqueum L.) dengan Cara Stek Batang. [Skripsi]. Surabaya: Universitas Negeri Surabaya.

Tarigan, P.L., Nurbaiti dan Yoseva, S. (2017). Pemberian ekstrak bawang merah sebagai zat pengatur tumbug alami pada pertumbuhan setek lada (Piper nigrum L). Jom Faperta, 4 (1), 1-11.

Trubus. (2010, 01 Mei). Semprot Saja ke Daun!. 14 November 2018, diunduh dari http://www.trubus-online.co.id/semprot-saja-ke-daun/.

Ulfa, 2014. Peran Senyawa Bioaktif Tanaman sebagai Zat Pengatur Tumbuh dalam Memacu Produksi Umbi Mini Kentang Solanum tuberosum L. Pada Sistem Budidaya Aeroponik. [Disertasi]. Makassar: Universitas Hasanuddin.

Wardoyo. 1996. Respon Pertumbuhan Stek Cabang Angsana (Peronema canescens Jack) Terhadap Posisi Penanaman dan Hormon Tumbuh Air Kelapa Muda. [Skripsi]. Bajarbaru: Universitas Lambung Mangkurat.

Whitmore, T.C. 1980. Potentially economic species of Southeast Asia forest. Jurnal Bio Indonesia, 7(1), $65-74$. 